\title{
教育講演
}

\section{THE HOSPICE, PHILOSOPHY, PROBLEMS AND DIFFICULTIES}

\author{
Merton Seigleman, M. B., B. Chir.,*
}

\section{DEFINITION}

The Hospice is a Unit specialising in the care and treatment of people suffering mostly from terminal illness, which is usually due to malignant diseasewhereby groups of dedicated people, Doctors, Nurses and others, undertake to relieve pain where this is present and improve the quality of life which remains for these patients. We are not really talking about a building, we are talking about a new concept in medicine. This new type of medicine is known as Hospice Care and for the first time attention is paid not only to the patient, but also to the patient's family. It must be stressed that these Units carrying out this type of care are not places where people go to die, but places where people go to have their quality of life improved and with the ultimate goal that they will be able to go home to be nursed at home by their families. A Hospice will often take in a patient to control a difficult symptom such as pain and when this has been dealt with the patient can return home. Similarly, a Hospice may take in a patient to give hard pressed relatives a well earned rest for a short period.

\section{PRINCIPLES}

The emphasis of this new type of treatment is the caring for patients when a cure is no longer available and the Hospice principles provide guidelines for this type of care. Terminal care has been a neglected area of medicine and it is only in recent years that people have begun to pay more attention to this illness. The old concept was that once cure was no longer available Clinicians took the view that "nothing more could be done". Times have changed, however, and now the new concept of treatment is that once the curative stage of treatment has finished, the caring stage begins. The objective is not only to relieve pain where this is present, but also to enable the patients to lead as good a life as we can possibly make. The advances in treatment of malignant disease in some cases cured patients, but in many others it meant that it greatly lengthened the time of ill-health and in many instances it leads to physical and mental suffering. However, with the advent of new drugs, with new forms of chemotherapy, with mew techniques 
derived from the Pain Relief Clinics and so on, it has been possible to greatly improve the lot of these patients. Hospice Care can be described as a combination both of professional expentise and human concern and a comprehensive care which is given both to patients and to the patient's family.

\section{HISTORY OF THE HOSPICE MOVEMENT}

The original meaning of the word Hospice was "a resting place for travellers". These were places where people who were journeying through the country stopped for the night after long journeys and at these Hospices they were replenished, refreshed and cared for, before continuing with their journeys. Very often they arrived sick and ill, sometimes wounded, and they were cared for at these places. However, the modern concept of the Hospice is completely different. A brief history of the Hospice : this shows that one of the first Hospices to be opened, was in 1846 in Dublin, Southern Ireland, where Irish Sisters of Charity opened an institution called Our Lady's Hospice and this included long-term patients and those suffering from incurable diseases, but they made their particular concern, the care of patients dying and I think that this is how the term Hospice has become equated with terminal illness. A number of Homes and Hospices were founded at the beginning of this century on both sides of the Atlantic to care for patients suffering from tuberculosis and cancer. The first purpose built Hospice was opened in London in 1967 by Dame Cicely Saunders. Dame Cicely was the guest lecturer whom you originally invited to talk to you, but unfortunately she was unable to come. Dame Cicely is probably the leading figure in the world at present as far as the Hospice Care is concerned. She had a lot of experience during the 1950's and 1960's working at various institutions in London, particularly at a Hospice called St. Joseph's. In 1967 she opened St. Christopher's Hospice in London which was built specially to cater for people with terminal illness. However, Dame Cicely streesed that the Hospice should have a mixed community of patients and, therfore, not only did she include terminal illness, but she also included people with such chronic illnesses as motor neurone disease, various neu-ro-logical complaints and some frail and elderly people. The view was that if the Hospice only catered for people who were terminally ill, then as soon as a patient was admitted to the Hospice he or she would know that she had a terminal illness and often these patients were unaware of what they were suffering from. Consequently, if it could be shown that there was a mixed community of patients, people suffering from various illnesses, then people would not appreciate that they were necessarily terminally ill. To quote from Dame Cicely "the care of the dying demands all that we can do to enable patients to LIVE until they die. It includes THE CARE OF THE FAMILY, THE MIND AND THE SPIRIT AS WELL AS THE CARE OF THE BODY. All are so interwoven it is hard to consider them separately." 


\section{OBJECTIVES OF TREATMENT}

The main objective of Hospice Care is to improve the quality of life of the patient and this can be achieved in the following ways:

1. To provide relief from pain by the administration of drugs at regular intervals. Not only physical pain, but psychological pain, spiritual pain and social pain. It is important to emphasise that these four different types of pain are for the first time being clearly defined.

2 . There should be care for the patient's family, in other words to provide supportive care where this is required.

3 . When the patients ultimately die they should have a good death, that is to say they should be free from pain and loneliness, they should be in a calm and familiar environment and they should have had the opportunity to discuss and be told the truth if this is what the patient wants. All too often in many cases of terminal illness there is a conspiracy of silence and this often increases the anxiety of the patient, it strains the relationships and increases the isolation of the patient. I think it is true to say that most patients would prefer to die at home if this is at all possible and so the ultimate objective is to enable the patients to return to their homes to be nursed and cared for providing adequate support is available.

\section{HOSPICE CARE CAN BE GIVEN}

Ideally, Hospice Care is best given in a purpose built Unit such as St. Christopher's or many of the other purpose built Units in the Country, my own included, but this is not absolutely vital and, therefore, one finds that in various different situations different forms of Hospice Care can be given and I would list them as follows:

1. A separate Unit such as St. Christopher's

2 . It may be part of a hospital, perhaps a whole ward

3 . Even just part of ward

4. Hospice Care can be given in the patient's home, in other words the patient's own General Practitioner looking after the patient with supportive care perhaps from Nurses coming from the Hospice.

5 . There may be simply what is termed as symptom control team. This occurs in a general hospital whereby a team of Doctors will go from ward to ward at the request of the Consultant-in-Charge of the patients, advising on the type of treatment to be given and making themselves responsible for the administration of this type of treatment.

As to which type of care patients will have will depend on local needs. If there are enthusiastic workers in a particular area, it may be possible to build a purpose built Unit. It depends just how great a need there is for this type of care in a particular area, but whichever type of Unit is used, the basic concepts remain the same, namely, to improve the quality of life 
of the patients who are ill.

\section{PRINCIPLES SPECIFIC TO HOSPICE CARE}

I shall now try to elaborate the principles which we have in mind when we undertake this new type of medicine.

1 . An expert team of Doctors is required, Doctors with a special knowledge of this type of medicine, Doctors who have specialised in the treatment of terminal illness and are experts in the treatment of the symptoms which these patients show. In addition they should be able to call upon the help of other Doctors, for example, Oncologists, Radiotherapists, Anaesthetist's Psychiatrists who may be needed for specific purposes. Being an Anaesthetist myself and being in charge of a Pain Relief Clinic, I find it advantageous to be able to apply the knowledge which I have gained from the Pain Relief Clinic and to apply it to my patients. This is a marked advantage because when, for example, nerve blocks are required, one doesn't have to call in the help of another Doctor and, therefore, it isn't necessary for the patient to have to establish another relationship with another Doctor.

2 . Nursing Care-without a doubt nursing care is the cornerstone of the Hospice Movement. It is necessary to have a skilled and experienced team of nurses who are specially selected for this type of work. There must also be experienced leaders of these nurses.

3 . The Hospice Team should include Physiotherapists, Radiographers, Pharmacists, Social Workers, Dieticians, also members of the Clergy. There will also be lay people who volunteer to do many of the tasks in the Hospice.

4 . There should be a Home Care or, as we call it, a Domiciliary Service for when the patients leave the Hospice to go home. when the patient goes home, he is then under the care of his own General Practitioner and the Community Nurses. The Hospice is there to provide support. The Hospice would be there strictly in an advisory capacity and is in no sense in opposition to the patient's own Doctor. The Hospice Team would be available 24 hours a day if required and there would be nurses who would be nurses who would go to the patient's home to visit them-these are known as the Domiciliary Nurses and act as a link between Hospice and home. The Social Workers and others would also be available to help the families with any social problems which may exist.

5 . Bereavement-there would be a bereavement follow-up service for the relatives of patients when they die. Social Workers, Chaplains, the patient's own Doctor and volunteers all can help soften the blow and make life easier for those who are left. Sometimes a husband may have attended to all the little chores in the house, such as how to. mend a fuse and so on and the wife is completely lost once her husband has gone. Conversely, the wife may have done all the cooking and when she dies her husband is unable to cook a meal or deal with the laundry. All 
these are problems which do arise and which can be helped enormously. This is an area which to date has been largely neglected. Usually when patients have died the hospital has taken no further interest in the remaining members of the family.

6 . Teaching-there should be teaching in all aspects of terminal care, teaching about drugs, of symptom control, of adjuvant therapy and there should be lectures and seminars organised. This is a new type of medicine which has not been taught in Medical Schools to date and, therefore, many people have much to learn and the Hospice can provide this centre of learning.

7 . There should be a consultative service whereby the Hospice can advise both Doctors in the hospitals and also General Practitioners when patients are referred to them. The advice should be both as to care and treatment and, when necessary, patients would be admitted into the Hospice.

8. Day care Facilities - these are facilities whereby patients can come in each day from their homes into the Hospice. They can have their treatment, their meals, their baths, etc and enjoy the company of the other patients. Sometimes these patients have already been in-patients and when they go home they are quite lonely and miss the company of the other patients and enjoy coming back to talk to them for a single day. On other occasions, it may well be that relatives have to go out to work and consequently patients would be left unattended during the day. However, if they can come back to the Hospice and be cared for during the day, they can go home in the evening and be at home with their families. The journeys are often undertaken in private cars by volunteers and the patients enjoy the drives both to and from the Hospice.

9 . The Unit itself should be built for specific purposes. The architecture should be of imaginative nature and many people have said that a Hospice should look like a really good class hotel rather than a hospital. The atmosphere inside, the decor, the decorations, the furniture, etc should not be clinical. Instead it should be of a warm nature. The object is to give a relaxed and an informal atmosphere as opposed to the clinical atmosphere of the acute hospital. Even if a ward is used for Hospice Care or even part of a ward, that can be tastefully furnished and tastefully decorated so that it would prove very comfortable for the patients to live in.

10. The administrative staff of the Hospice should be efficient and easily approachable so that they can answer questions from patient's relatives whenever required. This gives a sense of security for everyone involved.

11. Finally, there should be a mixed group of patients in the Hospice, not only patients dying from cancer. As stated earlier, it should include, if possible, long-term progressively ill patients, people with neurological complaints, paraplegics, etc. At St. Christopher's, because it is a large Unit, even old people and frail people are brought in, but this can only occur in a very large 
Unit. My own Unit consists of 10 beds and most of the patients are people with a terminal illness, but periodically we do take in patient's with motor neurone disease, paraplegics, etc just to destroy the impression that only the terminally ill come into the Unit.

All the above principles provide for the ideal type of Hospice, but it may not be always possible to achieve the ideal and it is true to say that a small amount of Hospice Care is better than none at all.

\section{THE ADVANTAGES OF A HOSPICE WITHIN A GENERAL HOSPITAL}

My own Hospice consists of a unit of 10 beds. This is a purpose built structure and is built in the grounds of one of our hospitals, but is situated apart from the other hospital buildings. In other words, it has its own privacy. I hope to show slides of the Hospice at the end of this lecture. The advantages of being attached to a general hospital are that we can receive all the facilities that the general hospital can offer, namely catering facilities, radiology, pharmacy, physiotherapy etc. If we were isolated from a general hospital, the Hospice would have to provide all these facilities and, therefore, the cost of maintaining the Unit would be much more expensive.

Most of the work of the Hospice is spent in dealing with the consequences of terminal malignant disease ensuring that whatever time is left to the patient, is time which the patient enjoys. No longer will one read of such statements as "they craved for sleep in order to relieve their pain and they dread the approach of the new day because of the pain it brings". No longer will there be any thoughts of people attempting suicide in order to relieve their pain. The drugs are available and the knowledge and skill of how to use these drugs is also available. No longer do we finish with the relatives once the patient has died. The reality is that many problems still remain for the patient's family. In fact, Dame Cicely Saunders says that when she admits patients into her Hospice, not only is the patient admitted, but she says that she also admits the patient's family as well, not literally, of course, but what she really means is that the whole of the family is treated as a basic Unit of care. Relatives are encouraged to be involved as much as possible and when bereavement occurs this is accorded priority which has never been known before. Nowadays, most patients are well controlled from a pain point of view and just die by peaceful relaxation of their grip on life.

\section{TREATMENT}

A brief word only about treatment. Most of the patients will be suffering from terminal malignant disease. These are patients who have already had active treatment, such as surgery, radiotherapy or chemotherapy and treatment is no longer available or in certain instances the diagnosis has been made much too late and active treatment is no longer possible. The situation has been reached where the emphasis is no longer on CURING but on CARING. Referrals to the 
Hospice come from two sources- a) from Consultant colleagues within the hospital or b) from General Practitioners. The methods of pain relief available are as follows :

1 . Nursing care and psychotherapy

2 . Analgesic and allied drugs

a) in the early stages mild analgesics and tranquillizers

b) in the late stages powerful narcotics in large doses

3 . Nerve blocks when indicated

4 . Deep x-ray therapy

5 . Chemotherapy

6 . Surgery - comparatively small procedures only, e. g. drainage of asites or drainage of a pleural effusion or drainage of an abscess. No major surgery is involved.

Most of the treatment is by drug therapy with nursing care forming the basis and essentials of all the care. No one single group of drugs is involved. It isn't simply a question of giving analgesic drugs, the whole of the patient must be treated.

Inappropriate treatment must be avoided. A Doctor has a duty to sustain life, but he has no duty either legally, morally or ethically to prolong the distress of a dying patient.

WHY THE NEED FOR A HOSPICE

I think at this stage before people become too bored with my talk, I shall discuss this next question of why there is a need for Hospice. Many people take the view that the Hospice is unnecessary, many Doctors say we can treat the patient just as well in the hospital ward or at home. So, may I stress that the views I put forward now are personal views and certainly open to discussion, comment and criticism and I should value all of these things. Terminal care is not taught in Medical Schools and consequently we become Doctors without having any guidance as to how to deal with patients suffering from terminal illness and it is true to say that the experience that we gain is often gained at the expense of patients. The Hospice movement has developed bcause there has been a gap in the normal provisions certainly in the National Health Service in Britain. Although hospitals and General Practitioners at home can give pain relief, it is the QUALITY OF PERSONAL CARE which puts the Hospice well ahead of the hospital. There is a need among Doctors for PSYCHO-SOCIAL SKILLS FOR CARING. This is not a matter of factual knowledge, but it is more a matter of imparting an attitude of mind and skills in communicating with and supporting people in distress. There is very little medical education which prepares students for dealing with the death of patients, when they become Doctors. However long a person may be a Doctor he may not necessarily acquire perhaps the skill and the ability to talk with the dying patient. It has been said and it is true, that some brilliant specialists are no good at terminal care and will never get better. Not every Doctor has the 
aptitude for handling patients who are dying. This is not to malign the Doctors concerned. Talking to a dying patient is an aptitude one has or has not. It is not something that one can learn from a book. Call it an attribute! In hospital there is less time for the kind of personalised attention and psychological support which the terminally ill patient requires. The routines of the ward and its organisation are geared to a different set of medical priorities. There is not even the assurance that the patient will receive the most effective pain control treatment in hospital. Death may even be regarded as a failure and there may be a tendency for hospital staff to withdraw from this kind of illness. One of the criticisms of hospital practices is that it concentrates on the physical symptoms of patients rather than on the human side of the patient. In other words, we are so busy concentrating on curative medicine that we tend to forget that caring for people is just as important. Let me concisely list the points whereby the Hospice is more advantageous than the acute ward.

1 . The emphasis on the acute ward is that of CURING for the patient. The emphasis in the Hospice is CARING. I suppose ideally medicine ought to have a balance between the two.

2 . In the acute ward of a general hospital it is difficult to treat the terminally ill patient a) Doctors and nurses often admit quite freely that they are unable to supply the highly personalised care which the patients need.

b) There is little time for giving support to relatives. It is important that relatives are brought fully up-to-date with what is happening to the patient. Meeting them is essential. They have to be prepared as to what will finally happen to the patient. They will have to be told how much they will have to do.

c) In Hospices relatives are encouraged to assist in the care of the patient and are allowed to visit freely throughout the whole of the day, whereas in an acute ward often relatives may well get in the way of the nursing staff.

3 . In the Hospice there is a much more pleasant atmosphere for the dying patient. He is not put in a corner of an acute ward as often happens with sometimes a screen put around to prevent the other patients from seeing the dying patient.

4 . Some Doctors, not all I would hasten to add, lose interest in a patient once they can no longer offer a cure. As mentioned earlier, the attitude taken is that there is"nothing more that we can do".

5 . There is an unwillingness by some Doctors to give the large doses of drugs which sometimes are needed. There are the fears of side-effects, for example, respiratory depression and addiction. All these fears have proved to be quite groundless because addiction does not occur in the terminally ill patient and respiratory depression, even with large doses of narcotics, have proved complete rarities. Therefore, specialist care is given by the Hospice Doctor who 
sees far greater numbers of this type of patient and, therefore, has developed a certain expertise. Some Doctors take the view that we can look after our own patients and some statistics from British Hospitals shows that the average family doctor with lists of perhaps 2,500 patients can expect approximately 6 cancer deaths a year. $60 \%$ of these will require only routine management whilst complex problems will occur rarely. In the Hospice, for example in my own Hospice, we have an average turnover of perhaps at least 200 patients a year and, therefore, the experience of the Hospice Doctors is much greater than that of the average Doctor.

6 . Statistics show that approximately $60 \%$ of patients with advanced cancer experience pain and some figures from St. christopher's Hospice in London show that $36 \%$ of patients has severe pain on admission, this figure fell to $8 \%$ after treament. The vast majority of patients coming into the Hospice in pain can have their pain completely controlled.

7 . Too many deaths in a ward sometimes disturbs the confidence of other patients and also the presence of the slowly and obviously dying also has a similar effect.

8 . Death sometimes can also be disturbing to both the nursing and the junior medical staff. They seem to feel that it indicates failure in their treatment.

Let me now turn to some of the facilities which Hospice Care can give and try and expand a little on these facilities.

\section{HOME CARE}

1. Hospice Care should help families to give terminal care at home. That is to say, patients would be admitted to the Hospice for short periods of time. When that patient's symptoms are under control, the patients will then be sent home to be looked after at home by the patient's own relatives, the Family Doctor and the Community Nurses.

2 . The housing should be suitable and there must be suitable care available, that is to say relatives, friends and volunteers to share in the nursing.

3 . The Family Doctor is in complete control when the patient is at home and he is in charge of the patient together with the District Nurses. The Hospice Team is available if requested in order to share symptom control.

4. The Home Care Team which is provided by the Hospice must be readily available by telephone and this is reassuring to the patient and the patient's family. By this I mean that sometimes patients can ring their own Family Doctor who may be off duty that particular evening or may not be available, whereas the Hospice is available 24 hours a day everyday and this is particularly reassuring to the patient and the patient's family.

\section{DAY CARE FACILITIES}

1. This is available for patients who are well enough to leave their homes and are brought 
in each day to the Hospice by car and then return home in the evening.

2 . They may come up daily or once or twice a week and this can bring some pleasure to the patient and help ultimately to improve the quality of the patient's life. They may have made good friends whilst in the Hospice and miss these friends. In coming back and seeing the Nurses and other friends this improves their appreciation of life.

3 . It is of great importance to those patients whose relatives go out to work or, in-some instances, even live alone. We don't send patients home if they are on very strong drugs and live alone. Those patients we would keep in the Hospice, but very often patients go home with adequate care by relatives, but sometimes relatives go out to work during the day.

4 . Families may have a hard time looking after their relatives and so perhaps once a week a visit to the Hospice will give the family a day off.

5 . The Day Care facilities are the appropriate treatments which the patients are having, baths, meals, the company of other patients, occupational therapy, hairdresser, beautician, all are available to the patient.

\section{CARE OF THE FAMILY}

1. Care of the dying should always include care of the family because there are many social problems which occur, for example, the breadwinner may have been admitted as a patient and consequently financial problems accrue and all of these problems come under the care of the Hospice Team.

2 . Close relatives should be given the opportunity to share in nursing the patient, under supervision of course. They should be shown the sort of drugs the patient is being given so that when the patient goes home the relatives will have full knowledge of precisely what drugs are and when they should be given and so on.

3 . The family should always be given opportunities to discuss their feelings regards the illness and the care of the patient.

4 . Caring for the families is best shared by Doctors, Nurses, Social Workers, Chaplains, etc.

5 . Free visiting is encouraged at all times, even children and grandchildren are encouraged to visit.

6 . Visits of the family pets are encouraged. For example, if a person has a dog to whom he is particularly attached, a visit by the dog to his owner would have tremendous psychological value to the patient.

7 . A drive out or a visit to the patient's home is to be encouraged if the patient is likely to stay in the Hospice for long period of time.

8 . Small things like remembering the patient's birthday or a wedding anniversary. All these things are to be encouraged. 
9 . The family should be encouraged to be at the bedside as death approaches because this is good, not only for the patient, but for the relatives because they no longer feel that they were not present at the last moment.

10. As stressed earlier, care of the patient's family will continue, even after the patient dies.

\section{HOSPICE CARE TEAM}

1. This is made up of Doctors, Nurses, Para-Medical Staff, Social Workers, Chaplain, Catering Staff, Volunteers, etc.

2 . Team work is essential. There should be good communication between all the different groups that go to make up the Hospice Team.

3 . Friction between team members will give a tense atmosphere and the patients will be able to sense this. The basis and essentials of a Hospice atmosphere is that it should be calm and it should be relaxed.

4 . The ideal nurse/patient ratio is $1: 1$. That is to say, if there are 10 in-patients there should be 10 nurses so that each shift there could be 3 nurses to cover the number of beds. This is an ideal number. The more nurses there are, the greater can be the personal attention given to each patient.

5 . The number of beds will vary, but in Britain ideally it is suggested that there should be between 45 and 50 specialist Hospice beds per million of the population. This is an ideal which is not always achieved.

6 . There should be periodic meetings of the staff so that all problems can be shared or successes can be shared and any problems that do exist can be fully ventilated. The object is to have a very informal and family-like atmosphere.

\section{HOSPICE CARE DIFFICULTIES}

1 . There is still within the medical profession the concept that curing a patient is the ideal and in many instances Doctors are still unwilling to accept that there comes a time when palliative care is the basis and essentials.

2 . Furthermore, some Doctors are still unwilling to prescribe the appropriate drugs on a regular basis for fear of side-effects.

3 . Funding and financing still presents a problem in Great Britain. Most of the Hospices are funded privately and this necessitates large amounts of money having to be collected annually. Fortunately, my own Hospice is part of our National Health Service and, therefore, is funded by the hospital.

4 . One of the difficulties still facing us is that some Doctors will not refer their patients for this type of care, they still have the feeling that they can look after the patients far better themselves. This is something that we have to live with. 


\section{STRESS}

In terminal care, emotional demands on the staff increase and this may lead to considerable stress. There is a current theory that each individual has a certain amount of energy for adapting to stressful situations and unless this supply of energy is regularly replenished, the supply becomes exhausted and then manifestations occur. The reasons for an increase in stress are as follows:

1. Failure to control the pain of the patient may make the staff feel guilty. They may become angry and depressed. They may wonder if the treatment is worthwhile, particulary if there are nasty side-effects.

2 . Personality changes or resentment by the patient may become difficult to bear.

3 . The members of the staff are expected constantly to give high standards of performance and very often these high standards may be difficult to keep up.

4 . The family of the patient may face very hard social problems and the staff may be unable to help and this can cause great stress.

5 . There sometimes may be difficulty in knowing where to draw the limit in involvement with patient and family.

6 . Repeated exposure with those coping with loss can lead to stressful situations MANIFESTATIONS OF STRESS

1. Physical signs-there may be exhaustion, fatigue, headaches, insomnia, gastro-intestinal disturbances, weight loss.

2 . Psychological-this may show itself in changes of mood, in depression, in anger, suspicion, loss of humour, inability to relax.

3 . There may be changes in attitude. There may be anger to co-workers, perhaps less concern to patients, perhaps they may even ignore patients, may even become hostile to some of the patients and their families.

4 . Relationships may change. Irritability, antagonism, avoiding other people, perhaps even marital problems.

5 . Change of work habit-there may ultimately become dissatisfaction with the work that they are doing. Perhaps they may absent themselves or perhaps go to the other extreme of spending more and more time with just a single patient.

6 . Change of habits-there may be loss of appetite, perhaps even over-eating, abandonment of recreation, increased smoking, perhaps the use of tranquillizers. All these things are manifestations of stress and, if observed, action should be taken.

\section{TREATMENT TO DIMINISH STRESS}

1 . One should always be looking round and seeing colleagues and whether there are any 
changes and, if changes do occur, they should become aware and respond to these changes.

2 . Careful staff selection will avoid much of the stress. In other words, to try and appoint people whom we think can cope with stress.

3 . There should be staff training and orientation. A new person should be put to work with a more experienced person to provide support for the new person.

4 . The goals and the priorities of the Unit should be clearly defined.

5 . There should be a multi-disciplinary approach so that many people should be responsible for the care of patients so that no one person need feel alone.

6 . There should be social support such as social activities, distractions, etc. It is important that the members of the Team are able to unwind, either at home or in support groups.

7 . There should be frequent meetings within the Hospice so that people can discuss problems, make suggestions, even have a Psychiatrist present on occasions to help solve some of the problems.

8 . There should be favourable working conditions. No unpredictable working hours so that Team members do not become exhausted.

9 . Above all else, the staff should be encouraged to retain their sense of humour. IT HAS BEEN SAID THAT LIFE IS GRIM, BUT NOT NECESSARILY SERIOUS.

\section{STRESS FOR THE PHYSICIAN}

1. Isolation. This occurs particularly in a Unit where there is only 1 Doctor. He can often feel very much alone.

2 . Role blurring-the Doctor may find himself acting as Social Worker, counsellor, friend, Priest and only for a short period does he find his true role as a Doctor.

3 . Repeated patient deaths may result in anger, denial, depression, resignation.

4 . The Doctor is all the time needing to be supportive to either patients, relatives or nurses and often finds himself with no support for himself and this can lead to great stress.

\section{VOLUNTEERS}

As mentioned earlier, volunteers do play a part in the successful working of the Hospice and I should like just to briefly mention the role of the volunteers.

1 . They do not replace permanent staff, they provide additional assistance.

2 . All skills and talents are welcome.

3 . The number of volunteers depends on the given situation and needs at a given time.

4 . Some of the tasks - a)they may help with nursing if they already have nurse training, b)they may assist with meals, c)make beds, d)sit and answer the telephone, e)sit and talk with the patients and read to them, comb their hair, f)visit bereaved families.

5 . All the volunteers are to have a probationary period to ensure that they do fit in well with 
the Hospice. It is important to stress that the volunteers are not some second class citizens, they form an integral part of the Hospice Team and can provide many different skills. They come from every walk of life and they can bring a vast array of gifts and skills which can compliment the gifts of the permanent staff.

\section{SOME GENERAL COMMENTS}

1 . There must be a constant review of the patients, daily when in hospice, weekly or more when at home because old pains may get worse and new paines may develop.

2 . Every patient must be treated as an individual. There is no standard treatment. Patients are given as much drugs as they need.

3 . The objective is to improve the quality of life. Threfore, we try and avoid procedures which cause a lot of discomfort, for example, tubes down the oesophagus, transfusions for long periods of time, etc.

4. We learn to improvise, for example, if a patient cannot swallow, we give them some ice to suck in order to get fluids into them.

5 . Whenever possible, patients are sent home from the Hospice once the symptoms have been relieved to be looked after by the relatives. The exceptions are people who live alone, where home circumstances are not good and relatives are unable to cope.

6 . The average length of stay in a Hospice is approximately $2-3$ weeks.

7 . There must be a constant link between patient and Hospice via the Liaison Sisters or Domiciliary Sisters. They act purely in an advisory capacity.

8 . Any drug to be taken home by the patients-we must note the dosage, time of the drugs to be taken, the colour of the tablets. All are written down on a card so that the patient is completely familiar and no mistakes are made.

\section{CONCLUSION}

The word Hospice has become an umbrella term for wide variety of provisions, in-patient care, home care, day care, bereavement counselling, training courses for medical and nursing staff. It is a new form of medicine with better control of pain by giving analgesic drugs at regular intervals, giving personal care to the patients and giving support for the families. One hopes that these new ideas will be spread far and wide to those Doctors who are unaware of how these forms of treatment are carried out. It gives the patient a choice, either weeks or months of pain-or dying free from pain.

It has been said that it is as much a MEDICAL SUCCESS to have a patient DIE IN COMFORT as it is to CURE HIM and see him walk out of the hospital. 